\title{
Eurasian Cold Surges Triggered by the Nonlinear Reflection of Stratospheric Planetary Waves in December 2012
}

\author{
Kunihiko Kodera $^{1}$ and Hitoshi Mukougawa ${ }^{2}$ \\ ${ }^{1}$ Institute for Space-Earth Environmental Research, Nagoya University, Nagoya, Japan \\ ${ }^{2}$ Disaster Prevention Research Institute, Kyoto University, Kyoto, Japan
}

\begin{abstract}
Eurasia experienced severe cold weather in December 2012. Particularly strong cold spells occurred in two regions: one over eastern Eurasia in early December, and the other in central to western Eurasia in mid-December. These extreme events were produced in association with blocking phenomena triggered by reflection or downward propagation of planetary waves from the stratosphere.

This event was unusual in that dominant component of upward and downward propagating wave is different: zonal wavenumber 2 component is dominant in the upward propagation; due to the amplification of zonal wavenumber 1 component in the upper stratosphere, zonal wavenumber 1 component becomes important in the subsequent downward propagation in the polar region. Identification of the tropospheric impact of the downward propagation of planetary waves is usually not easy. In the present case, however, the difference in the dominant zonal wavenumber between the upward and downward propagation facilitates to separate upward and downward propagation processes, and to isolate the amplification process of planetary waves in the upper stratosphere.
\end{abstract}

(Citation: Kodera, K., and H. Mukougawa, 2017: Eurasian cold surges triggered by the nonlinear reflection of stratospheric planetary waves in December 2012. SOLA, 13, 140-145, doi: $10.2151 /$ sola.2017-026.)

\section{Introduction}

Eurasia experienced severe cold weather in December 2012, whereas conditions were very warm over the contiguous United States. Such an anomalous temperature pattern differs to that related to the negative phase of the Arctic Oscillation, which brings cold air over Eurasia as well as North America (Thompson and Wallace 2000). During December 2012, particularly strong cold spells occurred twice in association with blocking events: once over eastern Eurasia from Lake Baikal to western Japan over the period 5-11 December, and the other from southern central Siberia to the Caspian Sea over the period 12-18 December, according to the Japan Meteorological Agency (JMA 2012).

Blocking itself is a regional-scale tropospheric phenomenon, and often occurs around the ridge of planetary-scale stationary waves through interaction with transient eddies, or due to the breaking of Rossby waves (Shutts 1983; Nakamura et al. 1997; Woolings et al. 2008; Yamazaki and Itoh 2009). Thus, the formation of blocking is not only influenced by regional conditions, but is also dependent on planetary wave structures (Austin 1980). Recent studies indicate that the reflection of planetary waves from the stratosphere can trigger blocking, especially over the PacificEurasian sector (Kodera et al. 2013, 2016; Nath and Chen 2016; Nath et al. 2016).

The influence on the troposphere of the reflection of planetary waves from the stratosphere has been demonstrated using singular vector decomposition and lagged correlation analysis (Perlwitz

Corresponding author: Kunihiko Kodera, Furo-cho, Chikusa, Nagoya, 464-8601 Japan. E-mail: kodera@ isee.nagoya-u.ac.jp. C2017, the Meteorological Society of Japan. and Harnick 2004; Shaw and Perlwitz 2013). However, because the tropospheric circulation itself evolves with time, ambiguities always remain regarding the physical processes that produce downward propagation and their impact on the troposphere. Also, although the extraction of a single wavenumber component, such as wavenumber 1 , from the eddy field facilitates the interpretation of reflection, it also obscures the relationship between the downward propagation of planetary waves and the tropospheric processes, including larger wavenumber components such as blocking.

In this paper, we will show that the blocking events that produced the severe cold spells over Eurasia in December 2012 were triggered by the downward propagation of planetary waves from the stratosphere. An intriguing characteristic of this event is that it was initiated by enhanced upward propagation of a wave packet from the troposphere in which zonal wavenumber 2 component is dominant, whereas zonal wavenumber 1 component becomes important due to its amplification in the upper stratosphere. Thus, the different wavenumber components in the upward and downward propagating waves facilitate the separation of the impact of the downward propagation of stratospheric planetary waves from the tropospheric variation.

The rest of the paper is organized as follows. After a description of the data in Section 2, our results are presented in Section 3, and a discussion and concluding remarks are given in Section 4.

\section{Data}

We used the meteorological reanalysis dataset created by the JMA, the Japanese 55-year Reanalysis (JRA-55; Kobayashi et al. 2015), for this study. We define anomalies as departures from the 30-year climatological mean (1981-2010), unless otherwise specified. The data have a horizontal resolution of $1.25^{\circ} \times 1.25^{\circ}$ and 37 vertical levels, of which 10 are above $100 \mathrm{hPa}$, with a top at $1 \mathrm{hPa}$.

\section{Results}

Eurasia experienced a period of extremely cold weather in December 2012. Surface air temperature anomalies exceeding twice the standard deviation of the interannual variation can be seen in Fig. 1a. Severe cold surges occurred in early December over East Asia and in mid-December over Central Asia. The daily minimum temperature was below $-24^{\circ} \mathrm{C}$ at Shenyang, China on 8 December, and below $-40^{\circ} \mathrm{C}$ at Astana, Kazakhstan on 15 December (JMA, 2012). The longitude-time section of surface temperature anomalies in the mid-latitudes $\left(35^{\circ} \mathrm{N}-50^{\circ} \mathrm{N}\right.$; Fig. 1b) shows that cold weather appeared periodically following the passage of migratory cyclones, but the two extreme cold spells mentioned above occurred when the cyclones became stationary, creating "blocking" events. This can be confirmed by the blocking strength index (Tibaldi and Molteni 1990), which is displayed as contours. The parameters used for the blocking strength index are identical to those used by Kodera et al. (2013).

To investigate the global environmental conditions for the formation of these blocking events, Fig. 2 shows the large-scale circulation related to the extratropical planetary wave activity. The amplitude of the zonal wavenumber 2 component of the 

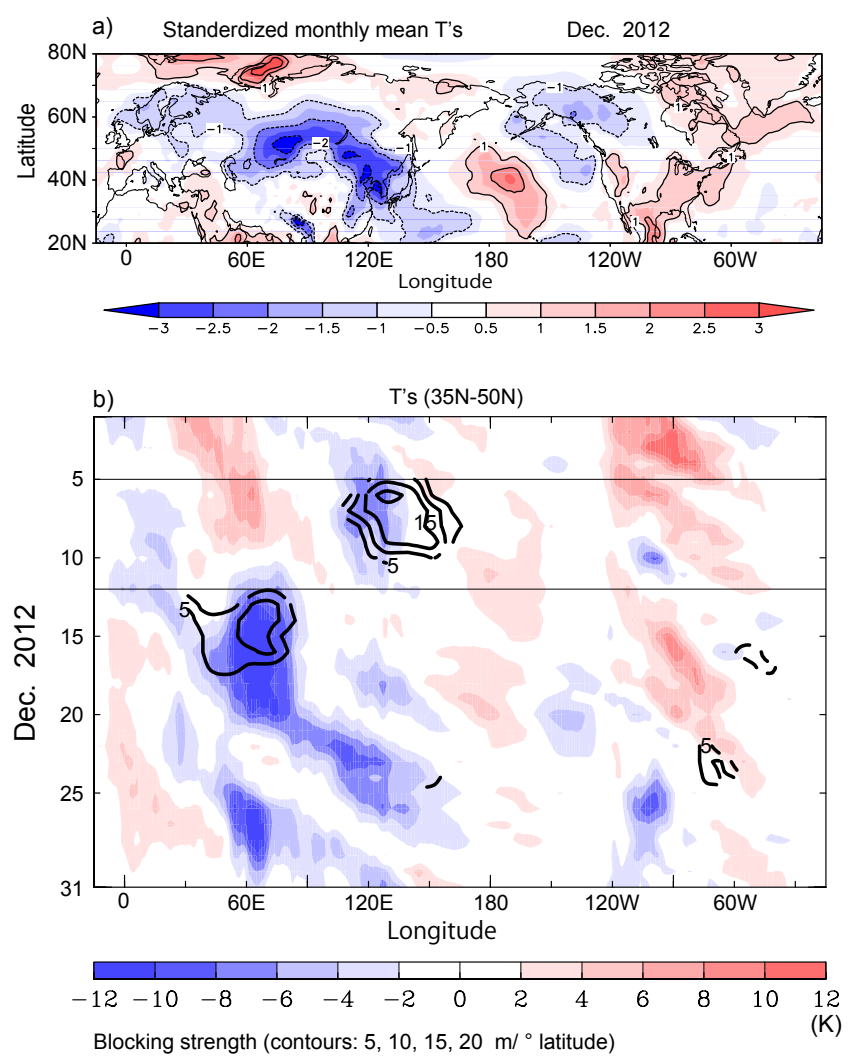

Fig. 1. (a) Standardized surface (2m) air temperature anomalies in December 2012. (b) Longitude-time section of anomalous surface air temperature averaged over $35^{\circ} \mathrm{N}-50^{\circ} \mathrm{N}$ (color shading). Blocking strength is indicated by contours. Horizontal lines indicate 5 and 12 December 2012.

geopotential height wave increased in the troposphere from the end of November (Fig. 2e) and propagated upward as indicated by the vertical component of the E-P flux (Fig. 2d). Accordingly, the North Pole temperature increased (Fig. 2a) and zonal winds decreased (Fig. 2c) in the stratosphere. However, zonal winds were only perturbed within the polar region because of the persistently strong zonal winds in the subtropical upper stratosphere (Fig. 2b). The zonal-mean zonal winds in the polar stratosphere started to recover from around 5 December in association with the commencement of downward propagation of planetary waves as indicated by the negative values of the vertical component of the E-P flux for both wavenumbers 2 and 1 (Fig. 2d). Note that the upward propagation of the wavenumber 1 component at $100 \mathrm{hPa}$ much weaker than that of the wavenumber 2 component during November, but downward propagation of the wavenumber 1 component was as large as that of wavenumber 2 as can be seen in Fig. 2d showing the vertical component of E-P flux averaged over north of $30^{\circ} \mathrm{N}$. Note also that in the polar region, wavenumber 1 component becomes dominant in downward propagation as will be shown later.

Evolution of the wave structure in the troposphere is depicted in the longitude-time section of the zonally asymmetric component of the $500-\mathrm{hPa}$ geopotential height in Fig. 2f. Inspection reveals that the zonal wavenumber 2 component dominated from late November until 3 December, with ridges around $0^{\circ}$ and $180^{\circ}$ longitude, and troughs around $90^{\circ} \mathrm{E}$ and $90^{\circ} \mathrm{W}$. Thereafter, while the Pacific ridge moved westward and merged with the European ridge, the Eurasian trough disappeared and the American trough extended westward over the Pacific. As a consequence of this transformation of the wave structure, the zonal wavenumber 1 component was amplified around 8 December. The cold spell over eastern Asia occurred as blocking developed (the locations are indicated by "B" in Fig. 2f) when the Pacific ridge moved over

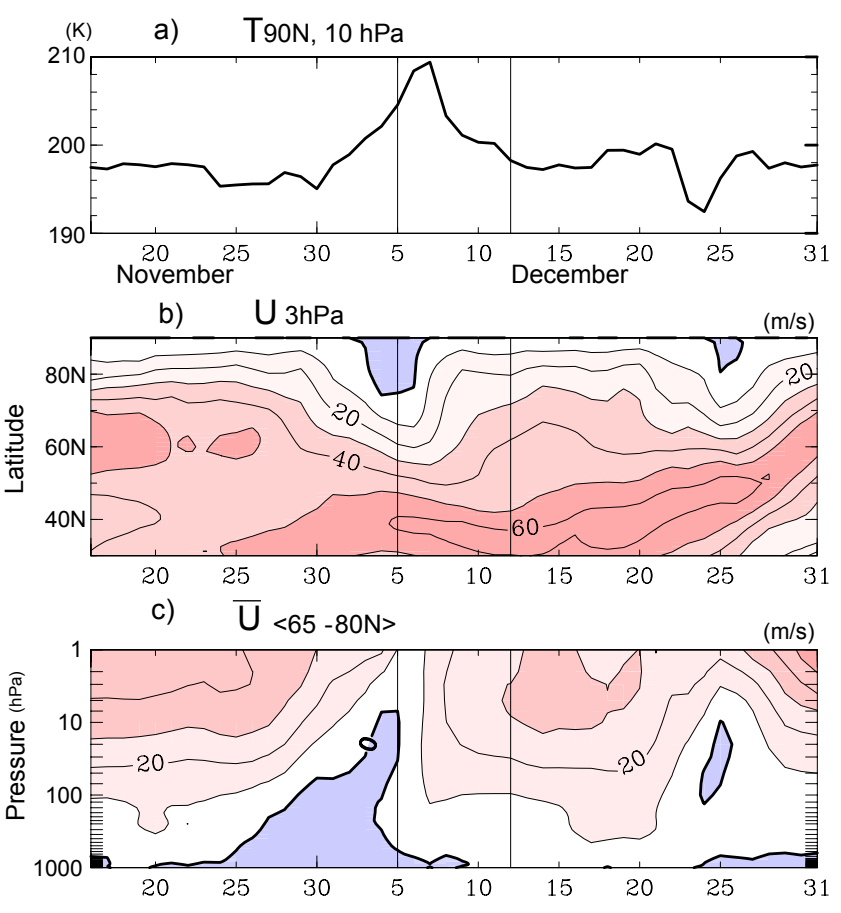

$\left(\times 10^{5} \mathrm{~kg} / \mathrm{s}^{2}\right)$ d) $\quad \mathrm{EPZ} 100 \mathrm{hPa} \quad<30-90 \mathrm{~N}>$
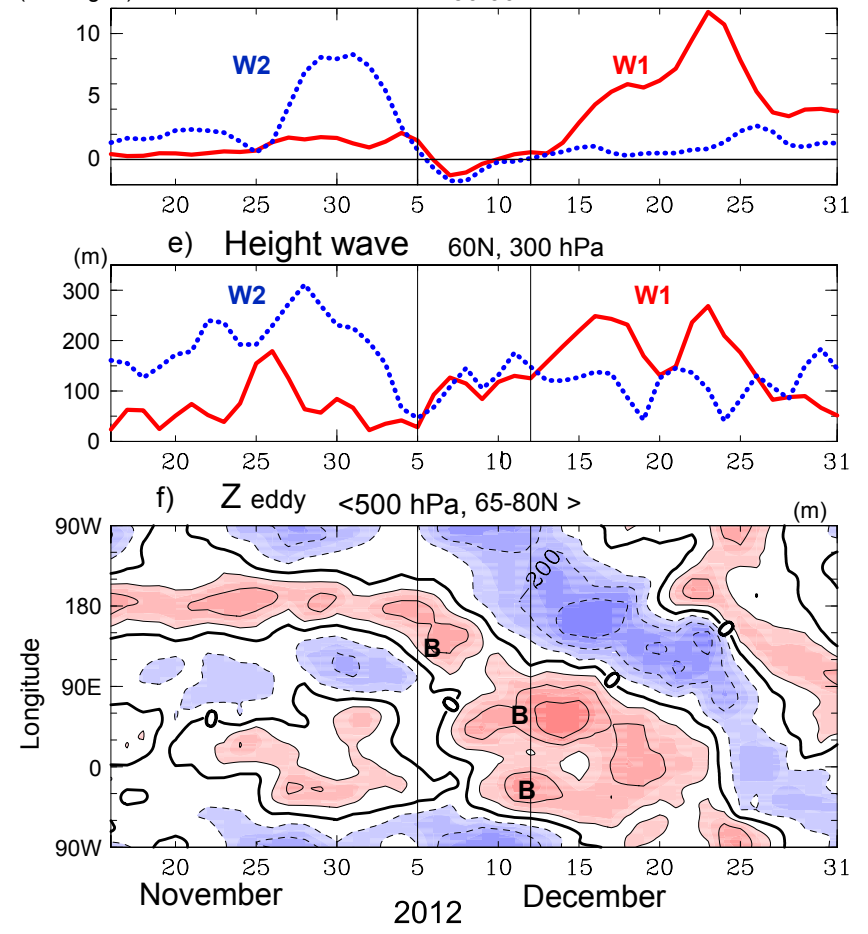

Fig. 2. (a) Time series of the North Pole temperature at $10 \mathrm{hPa}$. (b) Latitude-time section of zonal-mean zonal winds at $3 \mathrm{hPa}$. (c) Height-time section of zonal winds averaged over $65^{\circ} \mathrm{N}-80^{\circ} \mathrm{N}$. (d) Vertical component of the E-P flux at $100 \mathrm{hPa}$ averaged over $30^{\circ} \mathrm{N}-90^{\circ} \mathrm{N}$ for wavenumber 2 (blue line) and 1 components (red line). (e) Amplitude of geopotential height wavenumber 2 (blue line) and 1 (red line) components at $60^{\circ} \mathrm{N}, 300$ hPa. (f) Longitude-time section of the zonally asymmetric component of $500-\mathrm{hPa}$ geopotential height averaged over $65^{\circ} \mathrm{N}-80^{\circ} \mathrm{N}$. 'B' denotes the location of blocking. Vertical lines indicate 5 and 12 December 2012. 
Eurasia around 5 December, while the cooling in Central Asia started around 12 December following the development of another blocking ridge over central Eurasia.

The temporal evolution of the 3-day mean 500-hPa geopotential height and its anomalies from the climatology is shown in Fig. 3a. The ridge over the North Pacific extended to the north and then shifted westward from the beginning of December. On 7 December, the ridge was located over eastern Eurasia. The East Asian ridge then weakened while another ridge over Central Asia developed around 10 December. The Atlantic ridge also developed on 13 December after the Central Asian ridge. During the same period, a trough over eastern North America shifted westward and developed from the Russian Far East to Alaska. As a result of this transformation of troughs and ridges, a zonal wavenumber 1 structure became apparent in the $500-\mathrm{hPa}$ geopotential height field from 10 December.

Height-time sections of the zonally asymmetric component of the geopotential height averaged over $60^{\circ} \mathrm{N}-70^{\circ} \mathrm{N}$ are displayed in Fig. 3b. To illustrate the propagation of planetary waves, Plumb's (1985) wave activity fluxes due to wavenumber components 1-3 are shown as arrows in Fig. 3b. It can be seen that blocking develops around the ridges of the planetary waves.

At the beginning of December, there were two troughs: one around $110^{\circ} \mathrm{E}$ in eastern Eurasia and the other around $90^{\circ} \mathrm{W}$ in eastern America. The Eurasian trough tilted westward with height, whereas the trough in the American sector had little phase tilt with height. This shows that planetary waves propagated upward from the Eurasian sector as a wave packet (Hayashi 1980). The Eurasian trough then weakened and the Pacific ridge moved westward over the Eurasian continent from 4 to 7 December. The westward shift of the tropospheric ridge is produced in association with a downward propagation of planetary wave packet. The contribution of the wavenumber 2 and 3 components to the wave packet is important (Fig. 3a). Although similar westward shift of the tropospheric ridge can be seen in the wavenumber 1 component, its amplitude is still very weak on 7 December (Fig. 3b).

It should be noted that ridge and trough lines tilted opposite direction in the stratosphere and troposphere. This is clearly seen in wavenumber 1 component on 10 December. This means that while planetary waves propagate downward in the stratosphere,

b)
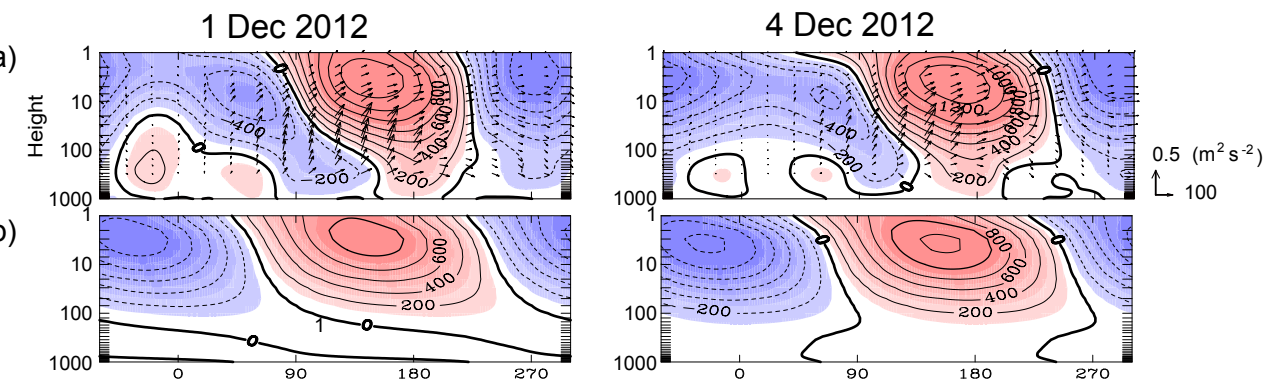

c)

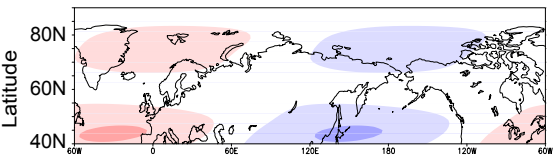

d)
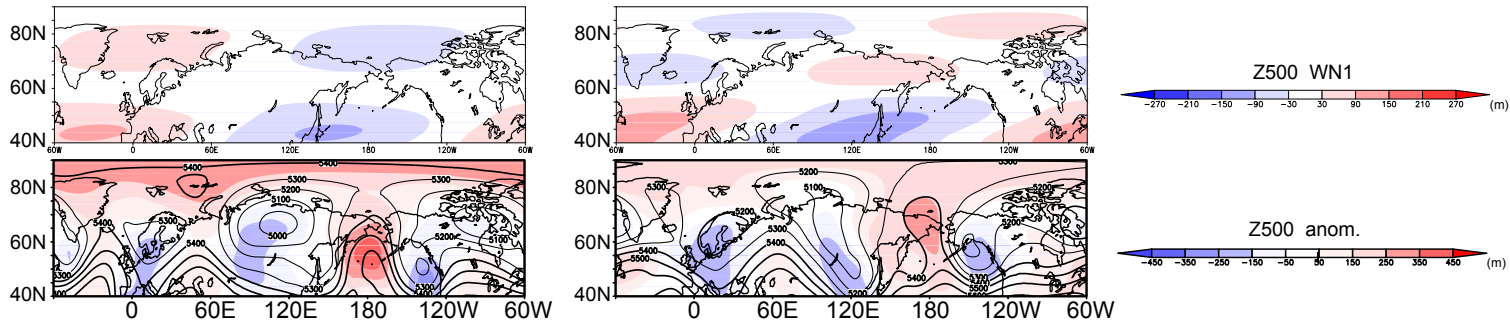

7 Dec 2012

a)

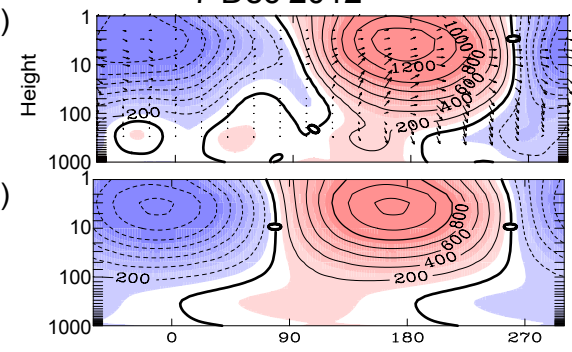

c)

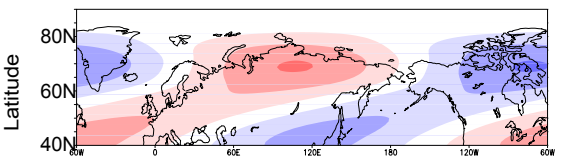

d)
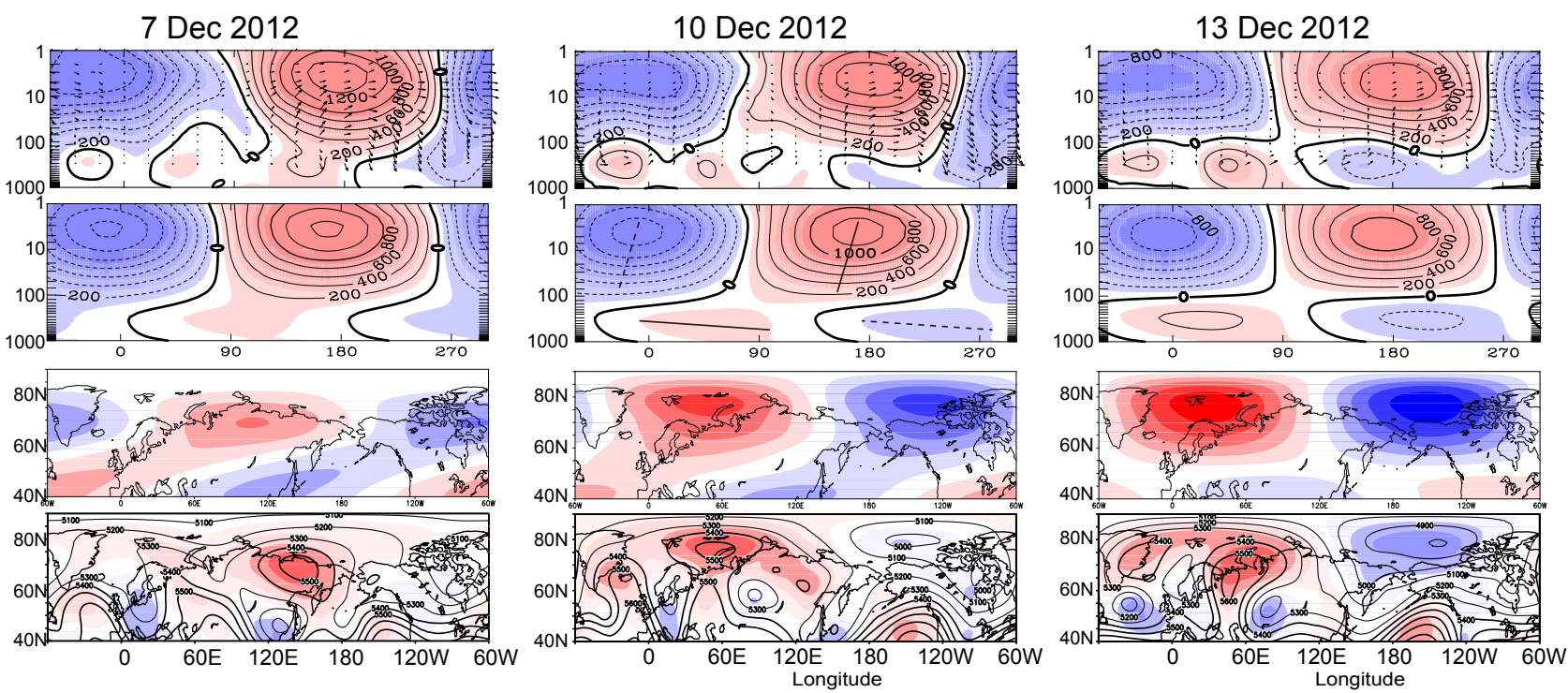

Fig. 3. (a) Horizontal distribution of 3-day mean 500-hPa geopotential height (contours) and its anomalies (color shading). (b) Height-latitude cross-section of 3-day mean zonally asymmetric component of geopotential height averaged over $60^{\circ} \mathrm{N}-70^{\circ} \mathrm{N}$. Arrows indicate wave activity flux for zonal wave components from 1 to 3 (Plumb 1985), scaled by the inverse of the square root of the pressure. Panels show 3-day means for, from top to bottom, 30 November2 December, 3-5 December, 6-8 December, 9-11 December and 12-14 December. Ridge and trough lines are indicated by solid and dashed lines, respectively, in Fig. 3b, 9-11 December. 
upward propagation continues in the troposphere. According to the interference between the upward and downward propagating waves, the amplitude of wavenumber 1 increases in the troposphere and the tilt of trough and ridge lines disappears on 13 December. This indicates that the wave becomes standing with opposite phases between the stratosphere and troposphere and a node at $100 \mathrm{hPa}$.

The upward propagation of the planetary waves is depicted by the E-P flux together with the zonal-mean zonal winds in Fig. 4a. The latitude-height sections for the E-P flux of zonal wavenumber components 2 and 1 , together with the perturbation height amplitude for each wave component, are displayed in Figs. $4 \mathrm{~b}$ and $4 \mathrm{c}$, respectively. Enhanced upward propagation of wavenumber 2 is evident on 1 December. The amplitude of wavenumber 1 is smaller in the troposphere, but increases with height in the stratosphere, although the wavenumber 2 component still dominates in the lower stratosphere. On 7 December, divergence of the E-P flux appears in the middle stratosphere, and is especially clear for the wavenumber 1 component. This occurs in association with the downward propagation of planetary waves from the stratosphere to the troposphere. A large increase in the amplitude of the wavenumber 1 component in the polar troposphere becomes evident on
13 December. The node structure with minimum amplitude around $100 \mathrm{hPa}$ is consistent with the reversal of phase around $100 \mathrm{hPa}$ in Fig. 3, suggesting interference between upward and downward propagating waves.

Our results suggest that the amplification of the zonal wavenumber 1 component originated in the upper stratosphere at the end of November. The evolution of the spatial structure of planetary waves in the upper stratosphere is also seen in the relative vorticity at $3 \mathrm{hPa}$ (Fig. 5). On 27 November, two negative (cyclonic) regions over Russia and Canada extended to lower latitudes where they shifted westward, implying the equatorward propagation of waves, as also seen in the E-P flux in Fig. 4. On 1 December, two cyclonic regions developed in association with reduced equatorward propagation indicated by a less tilted phase structure. On 5 December, the two cyclonic regions extended over the Atlantic and merged, forming a developed wavenumber 1 structure. Note that the relative vorticity changes sign around $45^{\circ} \mathrm{N}$ in the meridional direction, which indicates that the waves were trapped at high latitudes. Once downward propagation had begun, although the wavenumber 1 feature persisted, the amplitude of the eddy field reduced on 9 December. In contrast, an increase in the wavenumber 1 component was observed in the troposphere. Note
$25 \mathrm{Nov}$

a) U, EPF tot

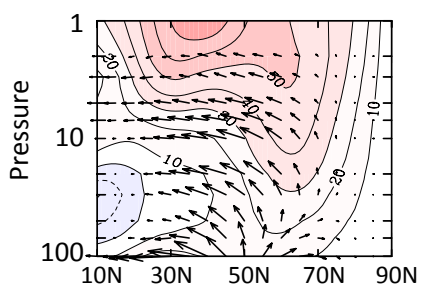

$1 \mathrm{Dec}$

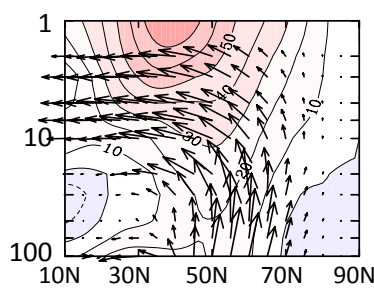

$7 \mathrm{Dec}$

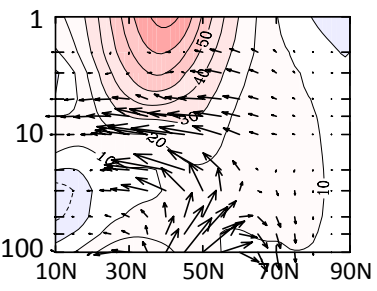

13 Dec 2012

3 day mean

b) W2
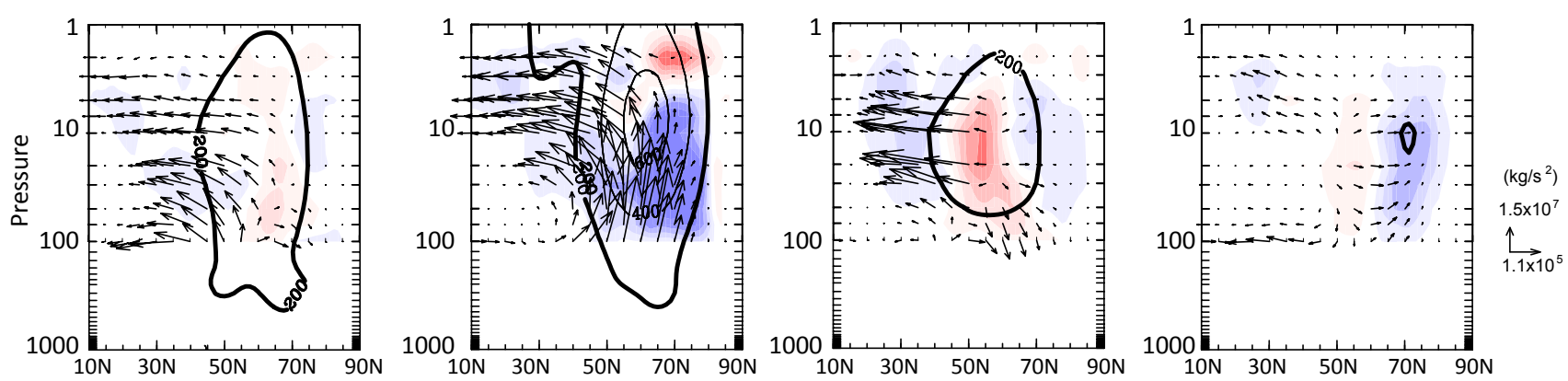

c) $\mathrm{W} 1$
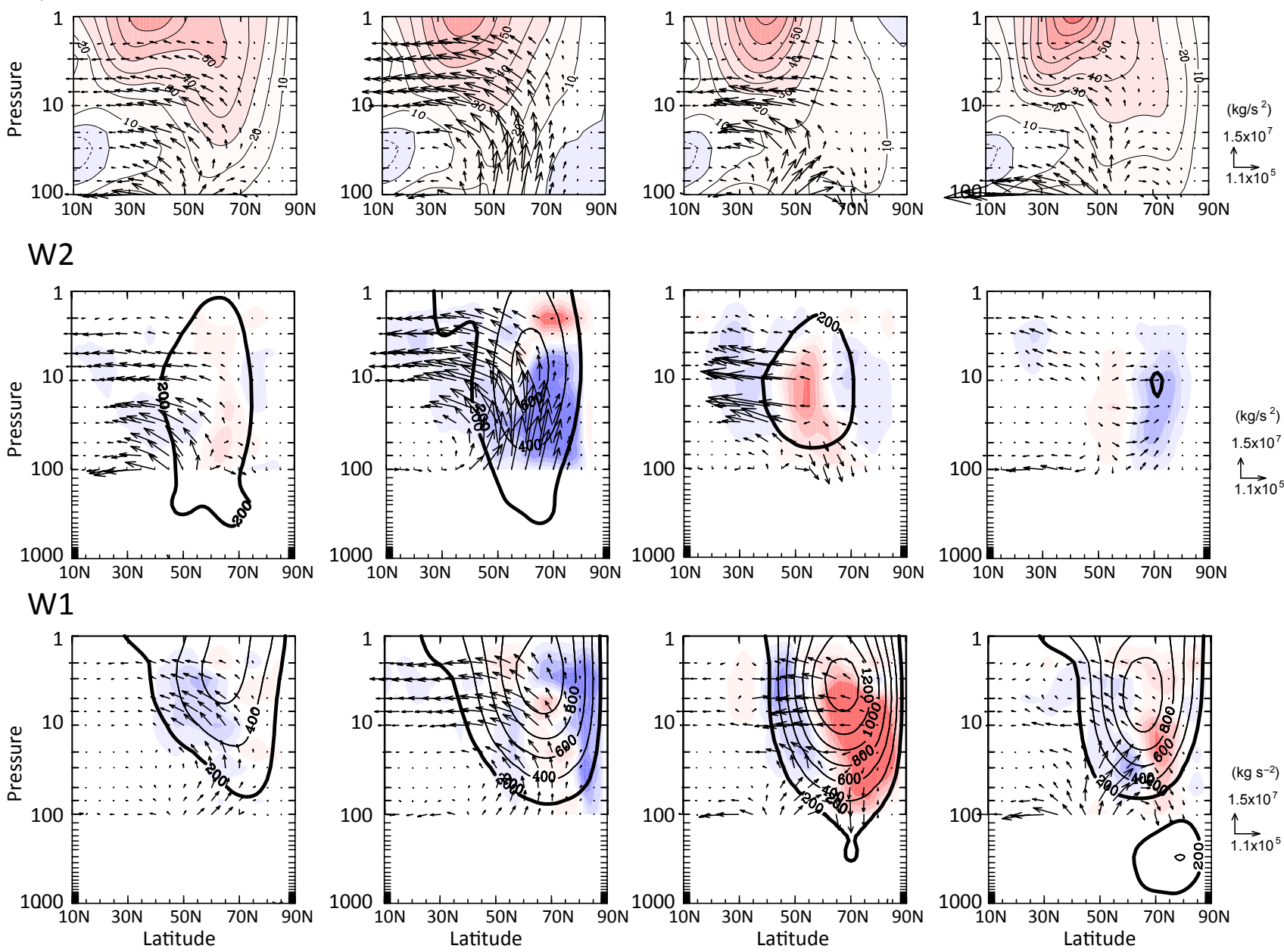

$\left(\mathrm{kg} / \mathrm{s}^{2}\right)$ $1.5 \times 10^{7}$ N

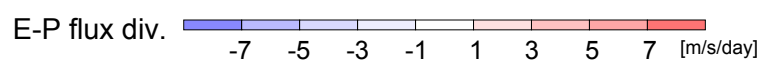

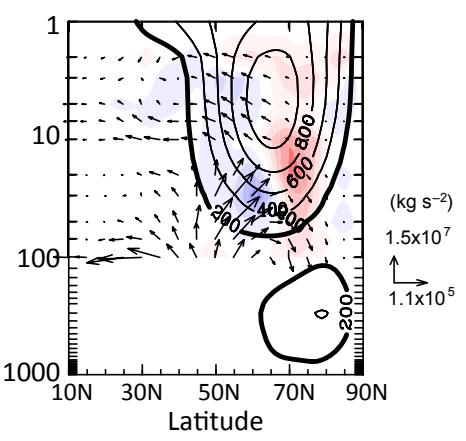

Fig. 4. (a) Zonal-mean zonal winds (contours) and total E-P flux (arrows). (b) E-P flux (arrows) and EP flux divergence (color shading) of wavenumber 2 component. Contours indicate amplitude of height wave for the wavenumber 2 component. (c) As (b), except for the wavenumber 1 component. The magnitude of the E-P flux is scaled by the inverse of the square root of the pressure. Panels show, from left to right, 3-day means of 24-26 November, 30 November-2 December, 6-8 December, and 12-14 December. 


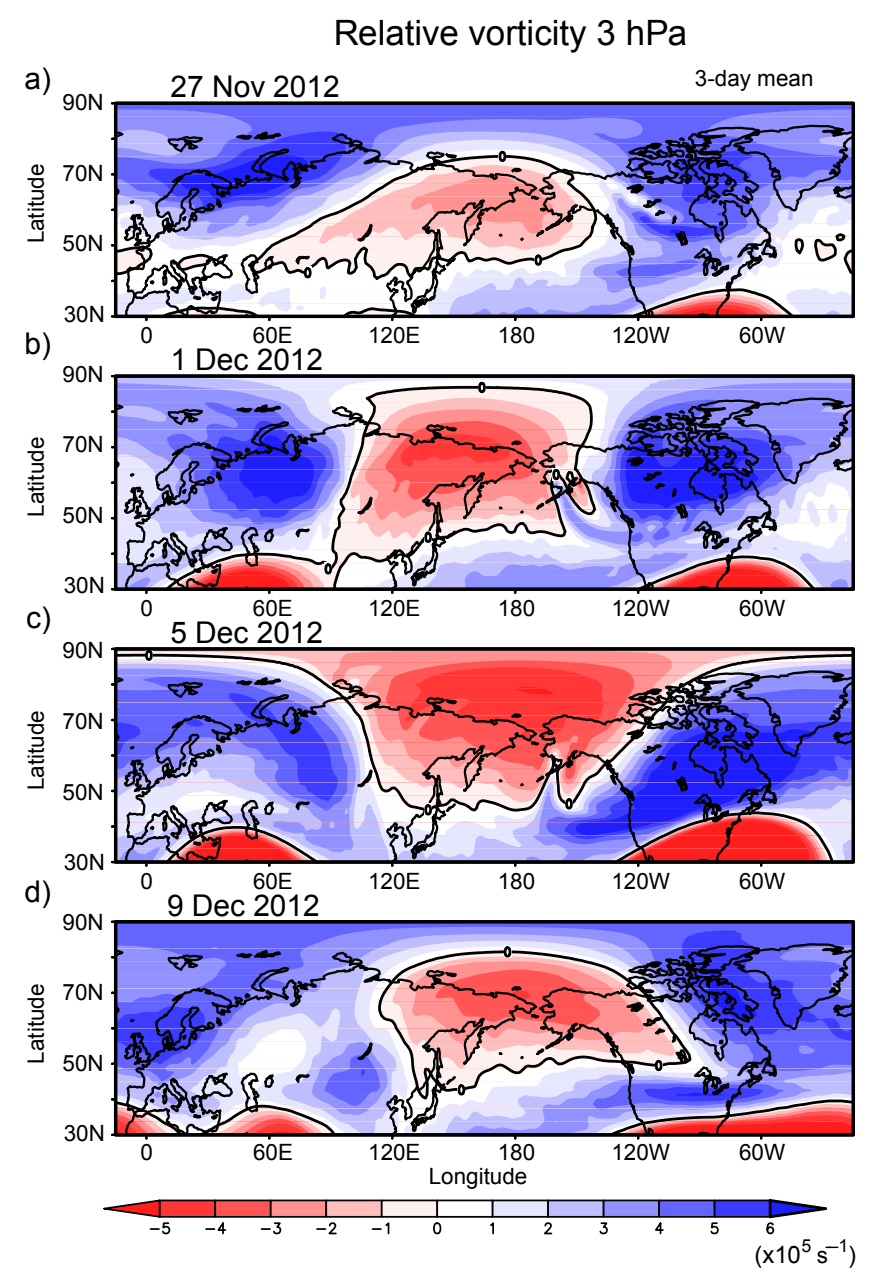

Fig. 5. Horizontal distribution of 3-day mean relative vorticity at $3 \mathrm{hPa}$. (a) 26-28 November, (b) 30 November-2 December, (c) 4-6 December, (d) 8-10 December 2012 .

also the slight changes in the phase structure of the stratospheric wave: a slight eastward tilt with increasing latitude over the Pacific-American sector indicating slight poleward propagation (Fig. 5d).

\section{Discussion and concluding remarks}

Cold surges over Eurasia in early- and mid-December 2012 were produced when large-scale blocking developed. The blocking occurred in association with the reflection of planetary waves from the stratosphere. The evolution of the propagation of planetary waves during December 2012 can be summarized as follows. i) Upward propagation of a wave packet with wavenumber 1-3 components from the Eurasian sector, which initiated the reflection event. ii) Downward propagation of the wavenumber 2 component followed by downward propagation of the wavenumber 1 component. iii) A large-scale tropospheric ridge over the eastern Atlantic-western Eurasia sector formed in association with an amplification of wavenumber 1 component as a result of the downward propagation of planetary waves.

The impact of the planetary wave reflection is seen at two stages in two regions. One is the Pacific-East Eurasian region, in which the reflection of the wavenumber 2 component in the lower stratosphere enhances the Pacific ridge and leads to the development of blocking over the Pacific and eastern Eurasian sector, which is a similar scenario to that reported in Kodera et al. (2013).
The second is the central and western Eurasian region, in which the reflection of the wavenumber 1 component from the upper stratosphere amplifies a ridge over central-western Eurasia and forms a block there. The two severe cold surges that developed in early- and mid-December 2012 over eastern and western Eurasia can be attributed to the former and latter types of reflection, respectively. The first stage of the event develops from the Pacific to the east cost of Eurasia, in which contribution of zonal wavenumber 2 is seen. This stage is similar to that studied in Kodera et al. (2013). We, therefore, focused here on the second stage over Eurasia, in which contribution of wavenumber 1 component becomes important.

As mentioned above, the vertical propagation of planetary waves occurs as a wave packet. Upward propagation of larger wavenumber components occurs under more restricted conditions than for smaller wavenumbers according to the linear theory (Charney and Drazin 1961). This means that the wavenumber 2 and 3 components of the wave packet should be reflected at lower levels before the wavenumber 1 component is reflected from the upper levels. This may explain why the Pacific-East Eurasian blocking event precedes the western Eurasian blocking event.

The ridge of planetary waves with the wavenumber 1 component has a wider longitudinal extent than the synoptic-scale blocking high. Indeed, it can be seen that the ridge of the wavenumber 1 component includes two blocking highs over the Atlantic and central Asian region on 13 December (Fig. 3). It is known that blocking amplifies planetary waves (e.g., Mukougawa et al. 2005; Martius et al. 2009). This example, however, clearly shows that the structure of the planetary wave influences the formation of blocking as discussed by Austin (1980).

Note also that the wavenumber 1 component has a node structure in both the vertical and horizontal directions, with a node around $60^{\circ} \mathrm{N}$ in the troposphere as well as in the upper stratosphere on 13 December (Fig. 3). This implies that the wavenumber 1 component is trapped in the polar region of the stratosphere and troposphere, which leads to its rapid amplification.

Westward shift of a ridge investigated by Kushnir (1987) is a phenomenon confined within the North Pacific sector and it is different from that investigated in the present study: westward shift of ridge across the Eurasian continent associated with the downward propagation of wavenumber 1 (Shaw and Perlwitz 2013; see also Fig. 10 of Kodera et al. 2016).

\section{Acknowledgements}

The JRA-55 reanalysis dataset was provided by the JMA and is available at http://jra.kishou.go.jp/JRA-55/index_en.html. Preliminary analysis in the present study used the ITACS system developed by the JMA. This work was supported in part by JSPS Grants-in-Aid for Scientific Research (S) JP2422401and (B) JP26287115.

Edited by: T. Hirooka

\section{References}

Austin, J. F., 1980: The blocking of middle latitude westerly winds by planetary waves. Quart. J. Roy. Meteor. Soc., 106, 327-350.

Charney, J. G., and P. G. Drazin, 1961: Propagation of planetaryscale disturbances from the lower into the upper atmosphere. J. Geophys. Res., 66, 83-109.

Hayashi, Y., 1981: Vertical-zonal propagation of a stationary planetary wave packet. J. Atmos. Sci., 38, 1197-1205.

Japan Meteorological Agency, 2012: Cold wave over the Eurasian continent in December 2012, Press release 28 Dec. 2012 (Available online at http://ds.data.jma.go.jp/tcc/tcc/news/ press_20121228.pdf, accessed 8 June 2017)

Kobayashi, S., Y. Ota, Y. Harada, A. Ebita, M. Moriya, H. Onoda, K. Onogi, H. Kamahori, C. Kobayashi, H. Endo, K. Miya- 
oka, and K. Takahashi, 2015: The JRA-55 Reanalysis: General specifications and basic characteristics. J. Meteor. Soc. Japan, 93, 5-48, doi:10.2151/jmsj.2015-001.

Kodera, K., H. Mukougawa, and A. Fujii, 2013: Influence of the vertical and zonal propagation of stratospheric planetary waves on tropospheric blockings. J. Geophys. Res., 118, 113, doi:10.1002/jgrd.50650.

Kodera, K., H. Mukougawa, P. Maury, M. Ueda, and C. Claud, 2016: Absorbing and reflecting sudden stratospheric warming events and their relationship with tropospheric circulation. J. Geophys. Res. Atmos., 121, doi:10.1002/2015JD 023359.

Kushnir, Y., 1987: Retrograding wintertime low-frequency disturbance over the North Pacific Ocean. J. Atmos. Sci., 44, 2727-2742.

Martius, O., L. M. Polvani, and H. C. Davies, 2009: Blocking precursors to stratospheric sudden warming events. Geophys. Res. Lett., 36, L14806, doi:10.1029/2009GL038776.

Mukougawa, H., H. Sakai, and T. Hirooka, 2005: High sensitivity to the initial condition for the prediction of stratospheric sudden warming. Geophys. Res. Lett., 32, L17806, doi: 10.1029/2005GL022909.

Nakamura, H., M. Nakamura, and J. L. Anderson, 1997: The role of high- and low-frequency dynamics in blocking formation. Mon. Wea. Rev., 125, 2074-2093.

Nath, D., and W. Chen, 2016: Impact of planetary wave reflection on tropospheric blocking over the Urals-Siberia region in January 2008. Adv. Atmos. Sci., 33, 309-318, doi:10.1007/ s00376-015-5052-4.
Nath, D., W. Chen, C. Zelin, A. I. Pogoreltsev, and K. Wei, 2016: Dynamics of 2013 sudden stratospheric warming event and its impact on cold weather over Eurasia: Role of planetary wave reflection. Sci. Rep., 6, 24174, doi:10.1038/srep24174.

Perlwitz, J., and N. Harnik, 2004: Observational evidence of a stratospheric influence on the troposphere by planetary wave reflection. J. Climate, 17, 4902-4909.

Plumb, R. A., 1985: On the three dimensional propagation of stationary waves. J. Atmos. Sci., 42, 217-229.

Shaw, T. A., and J. Perlwitz, 2013: The life cycle of northern hemisphere downward wave coupling between the stratosphere and troposphere. J. Climate, 26, 1745-1763.

Shutts, G. J., 1983: The propagation of eddies in diffluent jet stream: Eddy forcing of 'blocking' flow fields. Quart. J. Roy. Meteor., 109, 737-762.

Tibaldi, S., and F. Molteni, 1990: On the operational predictability of blocking. Tellus A, 42A, 343-365.

Thompson, D., and J. Wallace, 2000: Annular Modes in the extratropical circulation. Part I: Month-to-month variability. $J$. Climate, 13, 1000-1016.

Yamazaki, A., and H. Itoh, 2009: Selective absorption mechanism for the maintenance of blocking. Geophys. Res. Lett., 36, L05803, doi:10.1029/2008GL036770.

Woollings, T., B. J. Hoskins, M. Blackburn, and P. Berrisford, 2008: A new Rossby-wave breaking interpretation of the North Atlantic Oscillation. J. Atmos. Sci., 65, 609-626.

Manuscript received 30 March 2017, accepted 8 July 2017

SOLA: https://www.jstage.jst.go.jp/browse/solal 